\title{
Review Article \\ Effects of Surfactants on the Rate of Chemical Reactions
}

\author{
B. Samiey, ${ }^{1}$ C.-H. Cheng, ${ }^{2}$ and J. Wu ${ }^{2}$ \\ ${ }^{1}$ Department of Chemistry, Faculty of Science, Lorestan University, 68137-17133 Khoramabad, Iran \\ ${ }^{2}$ Department of Chemical Engineering, Ryerson University, Toronto, ON, Canada M5B 2K3
}

Correspondence should be addressed to B. Samiey; babsamiey@yahoo.com

Received 13 August 2014; Accepted 16 October 2014; Published 30 December 2014

Academic Editor: Tomokazu Yoshimura

Copyright (C) 2014 B. Samiey et al. This is an open access article distributed under the Creative Commons Attribution License, which permits unrestricted use, distribution, and reproduction in any medium, provided the original work is properly cited.

Surfactants are self-assembled compounds that depend on their structure and electric charge can interact as monomer or micelle with other compounds (substrates). These interactions which may catalyze or inhibit the reaction rates are studied with pseudophase, cooperativity, and stoichiometric (classical) models. In this review, we discuss applying these models to study surfactant-substrate interactions and their effects on Diels-Alder, redox, photochemical, decomposition, enzymatic, isomerization, ligand exchange, radical, and nucleophilic reactions.

\section{Introduction}

Self-organized assemblies such as micelles can change the rates of chemical and enzymatic reactions. Effects of micelles of surfactants on these reactions can be attributed to their electrostatic and hydrophobic interactions with reactants. Surfactants are amphiphilic organic compounds, containing both hydrophobic groups (their tails) and hydrophilic groups (their heads). Thus, a surfactant molecule contains both a water insoluble component and a water soluble component. The tail of most surfactants consists of a hydrocarbon chain. Surfactants are classified into four types. (1) Anionic surfactants, such as sodium dodecyl sulfate (SDS), contain anionic functional groups at their head, that is, sulfate, sulfonate and phosphate. (2) Cationic surfactants, for example, cetyltrimethylammonium bromide (CTAB), have cationic functional groups such as quaternary ammonium cation. (3) Zwitterionic surfactants have one cationic center and one anionic center both attached to the same molecule. The cationic part is based on primary, secondary, or tertiary amines or quaternary ammonium cations and the anionic part can be, for example, sulfonate and carboxylate [1]. (4) Nonionic surfactants (such as Triton X-100) do not ionize in an aqueous solution because their hydrophilic groups are nondissociable. Gemini surfactants (such as gemini 16-2-16) are a relatively new class of amphiphilic molecules containing two head groups and two aliphatic chains, linked by a rigid or flexible spacer [2]. They show greatly enhanced surfactant properties relative to the corresponding monovalent surfactants, Figure 1.

A micelle is an aggregate of surfactant molecules dispersed in a liquid colloid. Micelles form only when the concentration of surfactant is greater than the critical micelle concentration (CMC). This type of micelle is known as a normal-phase micelle (oil-in-water micelle). In a nonpolar solvent, a reverse micelle (water-in-oil micelle) forms in which the hydrophilic groups of surfactant are sequestered in the micelle core and the hydrophobic groups extend away from the center [3], Figure 2.

\section{Classification of Kinetic Models}

In this study, three models used to study kinetics of reactions in the presence of surfactants are discussed.

2.1. Pseudophase Model. The pseudophase (or pseudophase ion-exchange (PPIE)) model was first introduced by Menger and Portnoy [4] in 1967 to study effects of surfactant micelles 


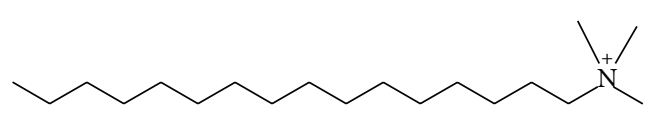

$\mathrm{Br}^{-}$

CTAB

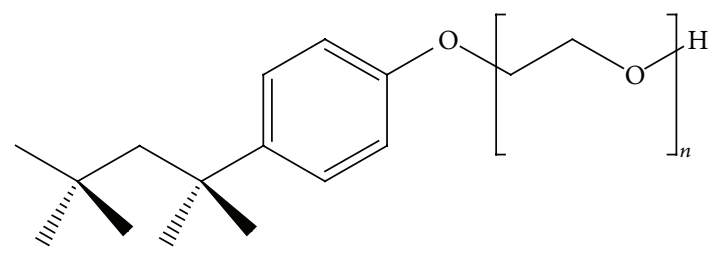

Triton X-100 (TX-100), $n=9-10$

Triton X-305 (TX-305), $n=30$ (avg)

Triton X-405 (TX-405), $n=40$

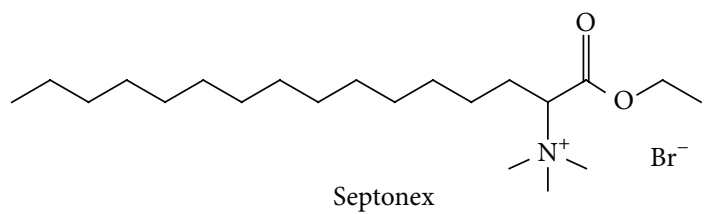

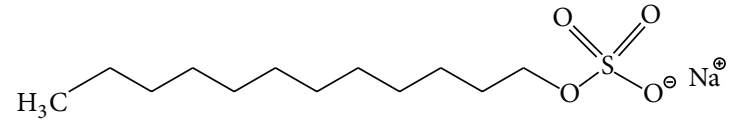

SDS

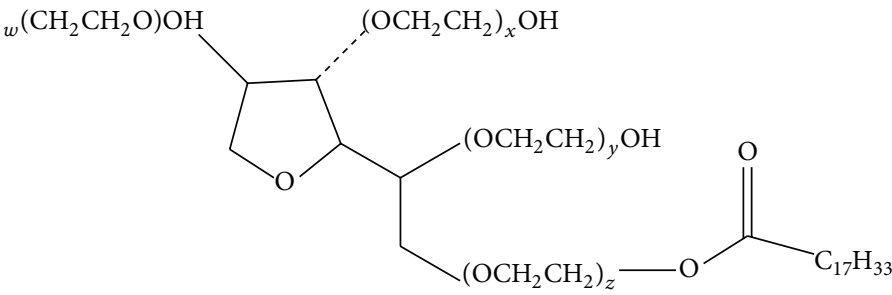

Where sum of $w, x, y$, and $z=20$

$$
\begin{gathered}
\text { Tween-80 } \\
\mathrm{C}_{16} \mathrm{H}_{33}-\mathrm{N}^{+}\left(\mathrm{CH}_{3}\right)_{2}-\mathrm{N}^{+}\left(\mathrm{CH}_{3}\right)_{2}-\mathrm{C}_{16} \mathrm{H}_{33} \\
\text { Gemini 16-2-16 } \\
\mathrm{CH}_{3}\left(\mathrm{CH}_{2}\right)_{6} \mathrm{CH}_{2} \mathrm{CH}=\mathrm{CHCH}_{2}\left(\mathrm{CH}_{2}\right)_{6} \mathrm{CH}_{2}\left(\mathrm{OCH}_{2} \mathrm{CH}_{2}\right)_{10} \mathrm{OH} \\
\text { Brij } 97
\end{gathered}
$$

FIGURE 1: Structures of several surfactants.

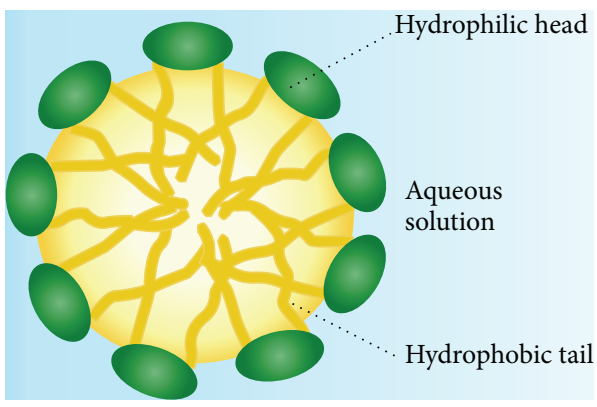

(a)

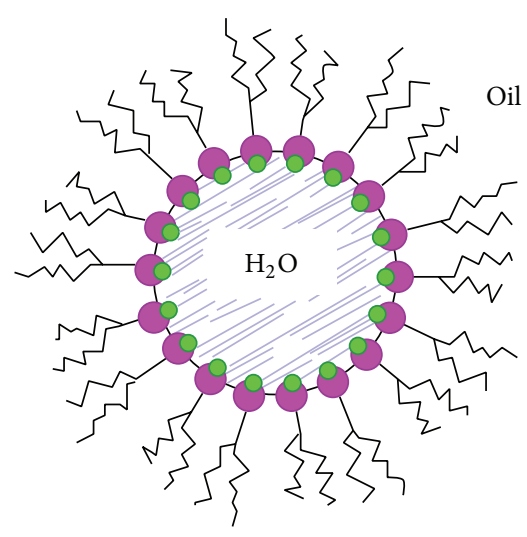

(b)

Figure 2: Typical structures of (a) micelle and (b) reverse micelle.

on the chemical reaction rates. They considered surfactant micelles as a pseudophase that can interact with some or all of reactants (or substrates), can further dissolve substrates, and can alter the reaction rate of substrates. Therefore, this model cannot study the interaction between the substrate and surfactant molecules below the CMC. With respect to the definition of micelle as a pseudophase, there is no stoichiometric ratio between the substrate and surfactant molecules for the presence of this interaction. The distribution constant of each substrate between solvent and micelle is defined as the binding constant of the substrate with a micelle. The substrate
$(S)$ distributes between the solvent and a micelle $\left(D_{n}\right)$ as follows:

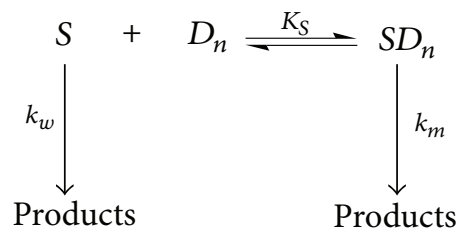

where $k_{w}$ and $k_{m}$ are the observed rate constants in the solvent and micelles, respectively. $K_{S}$ is the association constant of 
the substrate with the micelles. In this model, it is assumed that a single equilibrium relation, thus one $K_{S}$ value, is applied within the whole surfactant concentration range. On the basis of the above model, the following relation for the observed rate constant $\left(k_{\mathrm{obs}}\right)$ has been derived:

$$
\frac{1}{\left(k_{\mathrm{obs}}-k_{w}\right)}=\frac{1}{\left(k_{m}-k_{w}\right)}+\frac{1}{\left(k_{m}-k_{\mathrm{obs}}\right) K_{S}([D]-\mathrm{CMC})},
$$

where $[D]$ is the surfactant concentration. Depending on the number of substrates and other compounds (such as salts), relations of $k_{\mathrm{obs}}$ can be written as different forms.

2.2. Cooperativity Model. Piszkiewicz presented cooperativity model [5] in 1976 analogous to the enzyme-catalyzed reactions. This model is used only for reactions catalyzed by surfactants. He assumed that a micelle $\left(D_{n}\right)$ forms a noncovalent complex $\left(D_{n} S\right)$ with the substrate $(S)$ before the catalysis takes place:

$$
\begin{gathered}
D_{n}+S \stackrel{K}{\longrightarrow} D_{n} S, \\
D_{n} S \stackrel{k_{m}}{\longrightarrow} \text { products, } \\
S \stackrel{k_{0}}{\longrightarrow} \text { products, }
\end{gathered}
$$

where $K$ is the association constant of the micelle-substrate complex, $k_{m}$ is the rate constant for micelle-catalyzed reaction, and $k_{0}$ is the rate constant for the reaction in the absence of micelle. Similar to pseudophase model, this model assumed that there is only one equilibrium relation, thus one $K_{S}$ value within the whole surfactant concentration range. The $k_{\mathrm{obs}}$ at any concentration of surfactant is given by

$$
k_{\mathrm{obs}}=\frac{k_{0}+k_{m} K(([D]-\mathrm{CMC}) / n)}{1+K(([D]-\mathrm{CMC}) / n)},
$$

where $n$ is the number of surfactant molecules per micelle. Thus, this model can study interactions between the substrate and surfactant molecules above the CMC. An alternative cooperativity model, analogous to the Hill model applied to enzyme-catalyzed reactions, was proposed that the substrate and surfactant molecules aggregate to form micelles, $D_{n} S$, which may then react to yield product

$$
\begin{gathered}
n D+S \stackrel{K_{D}}{\longleftrightarrow} D_{n} S, \\
D_{n} S \stackrel{k_{m}}{\longrightarrow} \text { products, } \\
S \stackrel{k_{0}}{\longrightarrow} \text { products. }
\end{gathered}
$$

The model gives the following rate equation:

$$
\log \left[\frac{\left(k_{\text {obs }}-k_{0}\right)}{\left(k_{m}-k_{\text {obs }}\right)}\right]=n \log [D]_{t}-\log K_{D}
$$

where $K_{D}$ is the dissociation constant of micellized surfactant-substrate complex and $[D]_{t}$ is the total surfactant

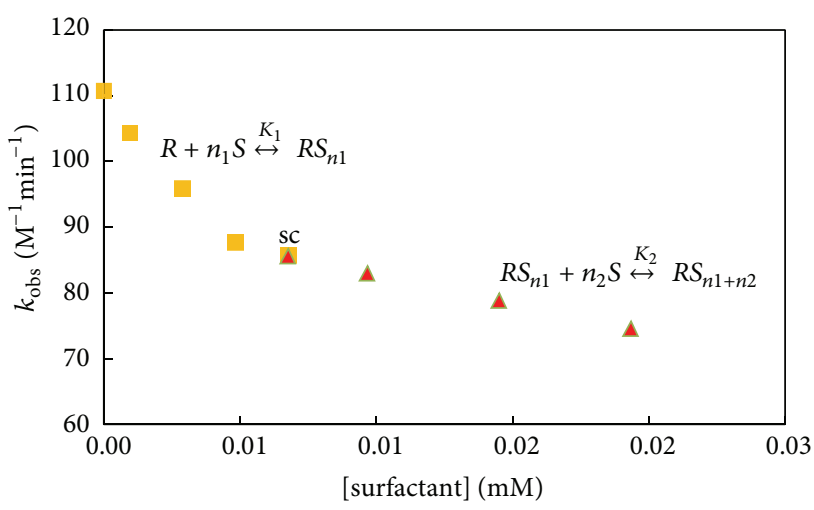

FIgURE 3: Typical equilibrium relations between reactant and surfactant molecules in a two-region system.

concentration. $n$ is known as the cooperativity index and is a measure of the association of additional surfactant molecules to an aggregate in the whole surfactant concentration range. If $n$ value is greater than one, the cooperativity of interaction is positive and if its value is less than one, the cooperativity of interaction is negative and if its value is equal to 1 , the interaction is noncooperative.

2.3. Stoichiometric Model. Samiey introduced the stoichiometric (classical) model [6] in 2004. In the stoichiometric model [6], it is assumed that, in each range of surfactant concentration, the surfactant and substrate can bind together and an equilibrium relation exists. The surfactant concentration in which the equilibrium relation between the added surfactant $(S)$ and the species already present in the solution $(R)$ ends and a new equilibrium relation between the added surfactant and the compound resulted from previous equilibrium relation $\left(R S_{n 1}\right)$ starts which is called "substratesurfactant complex formation point" (or abbreviated as sc point) and is as follows:

$$
\begin{aligned}
R+n_{1} S \stackrel{K_{1}}{\longleftrightarrow} R S_{n 1} \quad \text { (in the first region), } \\
R S_{n 1}+n_{2} S \stackrel{K_{2}}{\longleftrightarrow} R S_{n 1+n 2} \quad \text { (in the second region), }
\end{aligned}
$$

The CMC value of a surfactant is also a sc point and there may be some sc points higher and lower than CMC as well. The range of surfactant concentration which covers an equilibrium relation is named "region," Figure 3.

Surfactant molecules either monomeric or micellar can bind to the substrate molecules. Micelles can bind to the substrate by one or more number of their surfactant molecules. Thus, we can obtain the stoichiometric ratios and binding constants of interactions between surfactant molecules and with the substrate in various surfactant concentration ranges. The following equation holds for each equilibrium relation [6]:

$$
\ln k^{\prime}=c-\frac{E_{S}}{R T}[S]_{t},
$$


where $k^{\prime}, c,[S]_{t}, R$, and $T$ are the rate constant in the presence of surfactant, $\ln k$ (at first region) or $\ln k_{\mathrm{sc}}$ (for other regions), total surfactant concentration, universal gas constant, and absolute temperature, respectively. $E_{S}$ is the catalytic or inhibition energy of reaction at constant temperature and various surfactant concentrations. $k_{\mathrm{sc}}$ is the $k_{\mathrm{obs}}$ in the starting of each region except region one and $k$ is the $k_{\text {obs }}$ in the absence of surfactants. Equation (8) is introduced as "Samiey equation" [6] and determines the concentration range of each region. If the reaction rate decreases with the increase of surfactant concentration, the sign of $E_{S}$ is positive and is called "inhibition energy" and if the reaction rate increases with increasing the surfactant concentration, the sign of $E_{S}$ is negative and is named "catalytic energy" at constant temperature and various surfactant concentrations [6]. The unit of $E_{S}$ is $\mathrm{kJ}$ (mol molar (surfactant) $)^{-1}$. In this model, it is assumed that in each region one substrate molecule, $R$, binds to $n$ molecules of surfactant and we have

$$
R+n S \stackrel{K}{\longleftrightarrow} R S_{n}
$$

where $K$ is the binding constant of the substrate-surfactant interaction in each region. According to stoichiometric model, these interactions contain two types: Type I is the interaction of which surfactant molecules have an inhibitory effect on the reaction rate, yielding a decreased reaction rate; Type II is the interaction of which surfactant molecules exert a catalytic effect on the reaction rate, resulting in an increased reaction rate [6]. Some surfactants, show an increased reaction rate in a certain concentration range (type I) and a decreased reaction rate in the other range (type II). The $k_{\text {obs }}$, which indicates the interaction between one species of substrate with one kind of the surfactant, is species dependent and is related to the surfactant concentration as follows [6]:

$$
k_{\mathrm{obs}}= \begin{cases}\frac{k+k_{S} K[S]_{t}^{n}}{1+K[S]_{t}^{n}} & \text { (region one) }, \\ \frac{k_{\mathrm{sc}}+k_{S} K\left([S]_{t}-[\mathrm{sc}]\right)^{n}}{1+K\left([S]_{t}-[\mathrm{sc}]\right)^{n}} & (\text { all other regions) },\end{cases}
$$

where $k$ and $k_{\mathrm{sc}}$ are the $k_{\mathrm{obs}}$ in the absence of surfactant (beginning of the first region) and at each sc point, respectively. $k_{S}$ is the reaction rate constant in the substratesurfactant complex and is greater than reaction rate in pure solvent $(k)$ but when the surfactant has an inhibitory effect, $k_{S}=0$. Going from one region to the next one, if $K^{1 / n}$ value (the average binding constant of interaction between one substrate molecule and one surfactant molecule in each region) increases, the cooperativity of interaction is positive and if $K^{1 / n}$ value decreases, the cooperativity of interaction is negative. The total binding constant $\left(K_{\text {tot }}^{i}\right)$ and total stoichiometric ratio $\left(n_{\text {tot }}^{i}\right)$ values for each substrate, in the $i$ th region, can be obtained from following equations:

$$
\begin{gathered}
K_{\mathrm{tot}}^{i}=K_{1} \cdots K_{i-1} K_{i}=\prod_{j=1}^{i} K_{j}, \\
n_{\text {tot }}^{i}=n_{1}+\cdots+n_{i-1}+n_{i}=\sum_{j=1}^{i} n_{j} .
\end{gathered}
$$

Also, using this model we can study interactions of mixed micelles with substrate molecules and calculate the stoichiometric ratios and binding constants of their surfactant molecules with substrate molecules [6].

2.4. Comparison of Stoichiometric, Cooperativity, and PPIE Models. (1) In the PPIE model, the colloidal particles of surfactant (after $\mathrm{cmc}$ ) are considered as an ion exchanger and the binding of substrate to them is considered like the partition of a substrate between the two phases (micelle and solvent). In the PPIE and cooperativity models, the stoichiometric ratio of surfactant (as micelle) to the substrate is $1: 1$ and there is one average binding constant for substrate-surfactant compound in the whole surfactant concentration range, while in the stoichiometric model the stoichiometric ratio of surfactant (either micellar or monomeric) to the substrate is $n: 1$ and in each region there is a new equilibrium relation and therefore a new binding constant, a new stoichiometric ratio, and negative or positive cooperativity [6].

(2) The PPIE and cooperativity models is not applicable in the region before the $\mathrm{cmc}$ point of surfactant, but in the stoichiometric model the binding of substrate to the monomeric surfactant is considered.

(3) In the PPIE and cooperativity models, for the cases in which the reaction rate increases in one range of surfactant concentration and decreases in another range, it is assumed that in average there is one type of interaction between surfactant and substrate molecules. Therefore, there is one binding constant for whole range of the surfactant concentrations. But, in these cases, in the stoichiometric model it is assumed that the substrate molecules have different interactions with surfactant molecules and the reaction is catalyzed in one or more regions and inhibited in another region(s). Therefore, the binding constants are not identical in different regions.

(4) In the PPIE and cooperativity models, it is assumed that the rate constant in micelle $\left(k_{m}\right)$ is not usually equal to zero. But in the stoichiometric model, it is assumed that the rate constant in micelle for catalysis of reaction is more than the rate constant of free substrate and in the state of inhibition of reaction, it is equal to zero.

(5) In the PPIE and cooperativity models, only one sc point is assumed which corresponds to the cmc of surfactant. But in the stoichiometric model, there are various sc points including $\mathrm{cmc}$.

(6) In the PPIE and cooperativity models, the binding constant and stoichiometric ratio of single type substratesurfactant interaction are measured. But in the stoichiometric model, we can evaluate the stoichiometric ratios and binding constants of multiple type substrate-surfactant interactions in each region [6]. 
(7) In the stoichiometric model, $K$ values calculated for each region obey the Van't Hoff equation whereas the binding constants obtained from the PPIE and cooperativity models are not so in most of the cases.

\section{Change in the Chemical Reaction Rate in the Presence of Surfactants}

Interaction of surfactant molecules with substrates can result in decreasing or increasing the reaction rate or changing the yield of reaction and sometimes these surfactant molecules act as reactants. In this section, we discuss the role of temperature and cosolvents on the interactions between surfactants and substrates as well as the effects of head group, chain length, charge, and concentration of surfactants in a series of reactions, for example, Diels-Alder, redox, photochemical, decomposition, enzymatic, isomerization, ligand exchange, radical, and nucleophilic reactions. Furthermore, this section also discusses the potential role of surfactants as a reactant.

3.1. Diels-Alder Reactions. The Diels-Alder reaction is an organic chemical reaction (specifically, a $[4+2]$ cycloaddition) between a conjugated diene and a substituted alkene, commonly termed the dienophile, to form a substituted cyclohexene system. Because the majority of the diene and dienophile intermolecular Diels-Alder reactions have a rather pronounced nonpolar character, an efficient binding of both substrates to micelles is anticipated. This would imply that the effective reaction volume for the Diels-Alder reaction is significantly reduced, leading to micellar catalysis [7].

A study on the reaction of cyclopentadiene with a series of dienophiles shows the roles of charge and substituent groups in their interaction with surfactants [8-12].

In the reaction of acridizinium bromide (a cationic dienophile) with cyclopentadiene, a 10 -fold reaction rate is induced by anionic SDS micelles, whereas nonionic TX-100 and cationic 1- $N$-dodecyl-4-methylpyridinium bromide have only modest effects on the reaction rate [8]. The efficient catalysis by SDS most likely results from electrostatically enhanced binding of the dienophile to the micelles $[8,9]$. But the reaction rate of 1,2-dicyanoethylene with cyclopentadienedecreases with the increase of SDS concentrations which is due to weak interactions between 1,2-dicyanoethylene and SDS micelles [10]. It seems to point toward the Stern region of the micelles as the prominent site for this Diels-Alder reaction.

Rispens and Engberts [11] studied the reaction rate of cyclopentadiene with a series of $\mathrm{N}$-substituted maleimides in SDS micellar media. They observed that, up to $30 \mathrm{mM}$ of SDS, the reaction rate of cyclopentadiene with $N$-methyl maleimide is constant while its rate with $N$-butyl and $N$ benzyl substituted maleimideincreases with the size of substituent group. This is because the butyl and benzyl substituent groups lead to deeper solubilization of $N$-substituted maleimide in the SDS micelle compared to the methylsubstituted compound. Evidence suggests that the reaction in the micellar phase mainly takes place in the region between the core and the Stern layer, thereby still experiencing a polar environment. In all the above-mentioned cases, the apolar cyclopentadiene might be expected to mainly reside in the apolar micellar core. It was observed that if the SDS concentration is more than $30 \mathrm{mM}$, the reaction rate decreases. Pseudophase model considers just one kind of interaction occurring between SDS and substrate molecules within the whole SDS concentration range and calculated that $k_{m}$ value is less than $k_{w}$. However, it seems that pseudophase model fails to show that $k_{m}$ is greater than $k_{w}$ when the SDS concentration is less than $30 \mathrm{mM}$.

Simonyan and Gitsov [12] studied the first Diels-Alder reaction performed in an aqueous medium with highly hydrophobic compounds, such as fullerene $\left(\mathrm{C}_{60}\right)$ as the dienophile and anthracene or tetracene as the dienes, respectively. The reactions were performed in nanocontainers, constructed by self-assembly of linear-dendritic amphiphilic copolymers, Figure 4. Surfactants can also affect the endo/exoselectivity [13], regioselectivity [14], and enantioselectivity [15] of the Diels-Alder reactions.

3.2. Redox Reactions. The catalytic effects of SDS, NaBDS (anionic gemini surfactant), and mixed surfactants (SDS + $\mathrm{NaBDS}$ ) on the oxidation rate of $\mathrm{D}$-fructose by alkaline chloramine-T have been investigated [16]. The observed catalytic effect of mixed micelle on the oxidation rate was always less than the combination of the catalytic effects of two individual surfactants, suggesting an antagonism (negative synergism) in the mixed micelle. The antagonism has also been confirmed by determining the CMC and the interaction parameter $\left(\beta^{m}\right)$ of mixed micelle. According to the pseudophase model, $K_{S}$ and $k_{m}$ values of interaction of Dfructose with SDS were $8.2 \mathrm{M}^{-1}$ and $16.5 \times 10^{-4} \mathrm{~s}^{-1}$ and those of D-fructose with NaBDS were $400 \mathrm{M}^{-1}$ and $17.9 \times 10^{-4} \mathrm{~s}^{-1}$ at $35^{\circ} \mathrm{C}$, respectively.

The catalytic effects of zwitterionic micellar solutions of SB3-14 and SB3-16 on the redox reaction of $\mathrm{Br}^{-}+\mathrm{BrO}_{3}{ }^{-}$ have been studied using the pseudophase model [17]. The $K_{S}$ and $k_{m}$ values of $\mathrm{BrO}_{3}{ }^{-}$with SB3-14 were $310 \mathrm{M}^{-1}$ and $1.24 \times 10^{-3} \mathrm{~s}^{-1}$ and those of $\mathrm{BrO}_{3}{ }^{-}$with SB3-16 were $3100 \mathrm{M}^{-1}$ and $0.99 \times 10^{-3} \mathrm{~s}^{-1}$, respectively. In the presence of the same concentrations of surfactants, the reaction rate of using SB316 is less than that of using SB3-14. It seems that deeper solubilization of $\mathrm{BrO}_{3}{ }^{-}$in $\mathrm{SB} 3-16$ micelles decreases its reaction rate with $\mathrm{Br}^{-}$.

Vanadium (V) oxidation of D-glucose was studied in the presence of CPC, SDS, and TX-100 [18]. CPC inhibits the reaction, while SDS and TX-100 accelerate the reaction to different extents. The observed effects were studied by the cooperativity model and were explained by considering the hydrophobic and electrostatic interactions between the surfactants and substrates. Similarly, oxidation reactions of $\mathrm{Ce}(\mathrm{IV})[19]$ or oxyanions such as $\mathrm{CrO}_{4}{ }^{2-}[20,21]$ and $\mathrm{MnO}_{4}{ }^{-}$ [22] with organic compounds have been studied in the presence of surfactants.

Surfactants can affect the nucleation and growth kinetics $[23,24]$ and the reduction [25] of nanocompounds. For instance, colloidal silver particles in the nanometer size range were synthesized in ethanol, by the reduction of $\mathrm{AgNO}_{3}$ with nonionic surfactants Brij 97 and Tween 80 [25]. The main conclusion is that surfactants reduce silver ions to the 


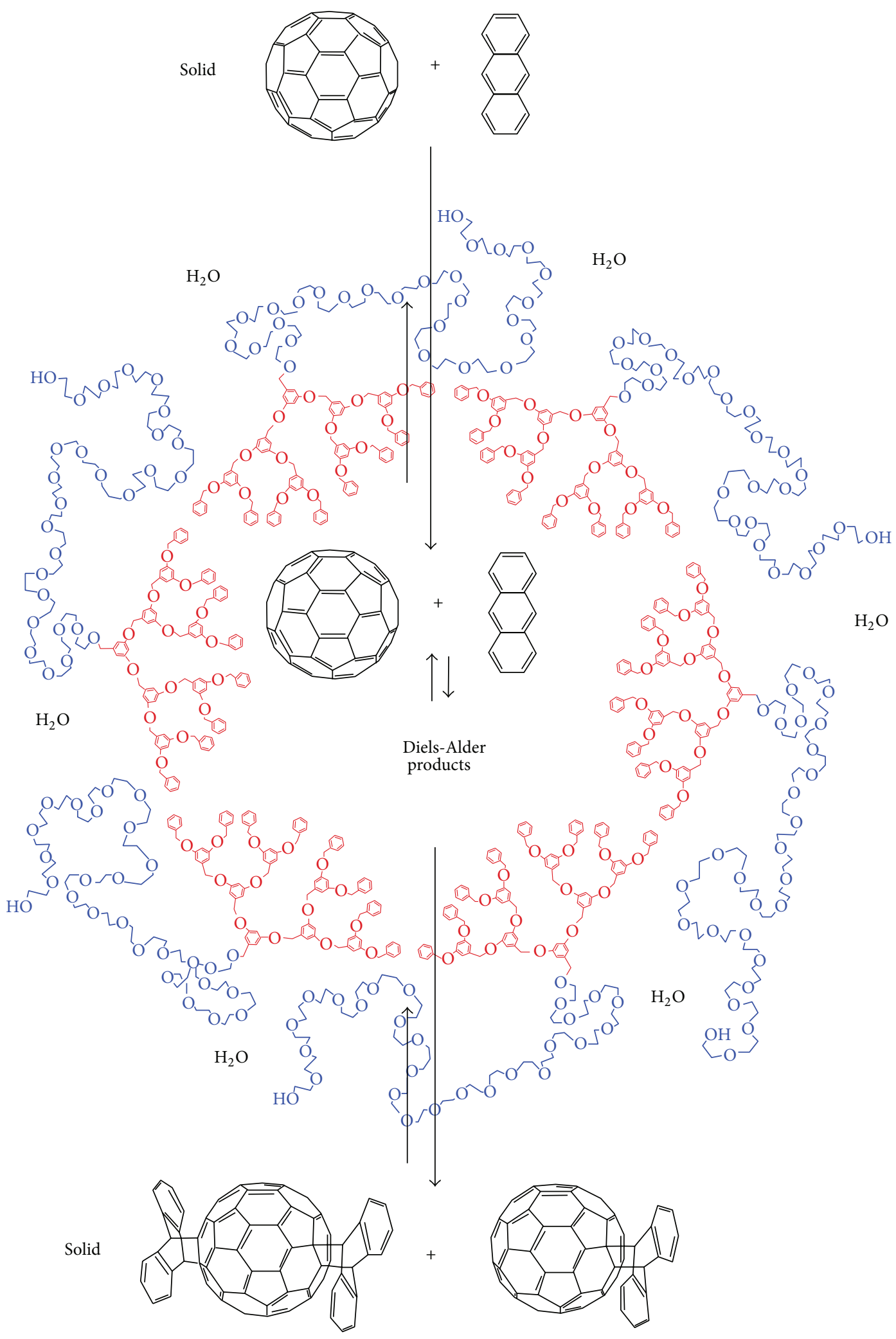

Figure 4: Mass transfer in and out of the micellar nanoreactor entity [12]. 
neutral state through the oxidation of oxyethylene groups into hydroperoxides. Surfactant molecules subsequently were adsorbed onto the surface of particles, promoting steric stabilization. This adsorption permits also the transfer of the particles into nonpolar solvents through a dry state where no particle aggregation occurs.

As reported [26-29], the electron transfer reaction was studied in the presence of surfactants. The electron transfer reaction between $\left[\mathrm{Co}\left(\mathrm{NH}_{3}\right)_{5}(\mathrm{~N} \text {-cyanopiperidine })\right]^{3+}$, pentaammine( $N$-cyanopiperidine)-cobalt(III), and hexacyanoferrate(II) has been studied in aqueous solutions [29]. The alteration of electron transfer rate constant in the presence of SDS, Brij 35, and TX-100 has been investigated at $298.2 \mathrm{~K}$. The rationalization of the experimental data was assisted by the use of the Marcus theory on electron transfer. The conclusion is that the micellar effects on the electron transfer rate constant can be explained by considering the micelles as a special background electrolyte with a high electric charge and a strong power of hydration.

Surfactants can affect the time stability of cation radicals $[30,31]$. As reported, the time stability of diethazine cation radical $\left(\mathrm{DE}^{+\bullet}\right)$ decreased in the presence of surfactants [30]. Below the CMC, Septonex (a cationic surfactant) monomers cannot interact with $\mathrm{DE}^{+\bullet}$ and do not affect the degradation rate. Above the CMC, the $\mathrm{DE}^{+\bullet}$ degradation is catalyzed by Septonex micelles that are able to bind to $\mathrm{DE}^{+\bullet}$ particles through hydrophobic interactions, without associating with $\mathrm{H}^{+}$ions. The $\mathrm{DE}^{+\bullet}$ degradation, occurring in the micellar pseudophase relatively poor in $\mathrm{H}^{+}$ions, is therefore much faster. The effect of nonionic surfactant TX-305 is similar with the cationic surfactant but less significant. On the other hand, the associations of $\mathrm{DE}^{+\bullet}$ with SDS premicelle aggregates which do not bind to $\mathrm{H}^{+}$ions formed below the CMC of SDS and the rate of $\mathrm{DE}^{+\bullet}$ decomposition quickly increases with the increase in SDS concentration. For the concentrations of SDS higher than the $\mathrm{CMC}, \mathrm{DE}^{+\bullet}$ radicals are bound to the negatively charged surface of micelles, together with $\mathrm{H}^{+}$ions. Therefore, the $\mathrm{DE}^{+\bullet}$ decomposition reaction is inhibited at higher surface local $\mathrm{H}^{+}$activity and the $\mathrm{DE}^{+\bullet}$ degradation rates decrease.

3.3. Photochemical Reactions. The solutions of 3-(4-chlorophenyl)-1,1-dimethylurea (monuron) were photolyzed in aqueous media containing nonionic surfactants [32]. The TX100 , TX-405, TMN-6, and TMN-10 were used to elucidate the influences of aryl- and alkyl-substituted polyoxyethylene glycol surfactants. Concentrations of all surfactant solutions were above each individual CMC. Samples were examined under oxygenated and nonoxygenated conditions. The presence of surfactants enhances the degradation rate of monuron, eliminates ring hydroxylation reactions, and promotes the reductive dechlorination reaction. Monuron is adsorbed on the lyophilic surface or into lipophilic core of micelles. Similar to that observed for the photolysis of nitroaromatic [33] and 2-chlorophenol [34] compounds, the results indicate that these photochemical reactions occur in the organic phase of the micelles rather than the aqueous phase of the solvent. In addition to the interaction with substrate, surfactants can sometimes act as an additional source of hydrogen for the reaction $[35,36]$.

The $\mathrm{TiO}_{2}$ photosensitized oxidation of 4-dodecyloxybenzyl alcohol, which is water insoluble, was investigated in aqueous solutions of anionic, cationic, and nonionic surfactants [37]. The reaction, which is practically absent in water, is greatly enhanced by several surfactants at concentrations higher than CMC and the effect is strongly dependent on the nature of the surfactant. The increase of surfactant concentration leads to more substrate molecules, solubilized in micelles, which are transported close to the $\mathrm{TiO}_{2}$ particle surface where the photooxidation reaction takes place. After a certain concentration which varies with the nature of the surfactant, the presence of competitive partition of comicellized 4-dodecyloxybenzyl alcohol (substrate) between $\mathrm{TiO}_{2}$ surface (where the reaction occurs) and bulk solvent tends to diminish the beneficial kinetic effect of surfactant.

For $N, N, N^{\prime}, N^{\prime}$-tetramethylbenzidine solubilized in mixed micelles of C12E6/SDS or C12E6/DTAC, the electron spinecho and electron spin resonance spectra of photogenerated cations show that the photoionization yield depends on the sign of net charge of the mixed micelle and on the strength of the photocation-water interaction [38]. It is found that the photoyield is enhanced by the presence of mixed micelles with a net positive charge, probably due to the fact that electron escaping from the micelle is facilitated in cationic micelles.

Photogalvanic effects were studied in photogalvanic cells containing SDS as a surfactant, EDTA as a reductant, and azur-B as a photosensitizer [39]. The used SDS solubilizes the dye more easily and stabilizes the system and may increase the probability of charge transfer between the surfactant and the dye in the system compared to the tunneling of photoelectrons from the micellar phase to the aqueous phase.

3.4. Decomposition Reactions. In the presence of SDS micelles, 1-naphthalenediazonium $\left(\mathrm{ArN}_{2}^{+}\right)$is incorporated into the micellar aggregates, given the estimated $K_{S}$ of $290 \mathrm{M}^{-1}$ and $k_{m}=9 \times 10^{-4} \mathrm{~s}^{-1}$. It shows that a significant fraction of 1-naphthalenediazonium is incorporated into the micellar pseudophase at low-surfactant concentrations, where it undergoes thermal decomposition in the Stern layer [40].

Brinchi et al. [41] studied the decarboxylation of anionic 6-nitrobenzisoxazole-3-carboxylate (6-NBIC) and its 5 -methyl derivative (6-NBIC-5-Me) in the presence of a series of several cationic cetyltrialkylammonium bromide surfactants including $\mathrm{CTAB}, \mathrm{CTEAB}, \mathrm{CTPAB}$, and $\mathrm{CTBAB}$, Figure 5.

Cationic micelles of cetyltrialkylammonium bromide facilitate the decarboxylation of both 6-NBIC and 6-NBIC-5Me by decreasing activation enthalpies. It was observed that the reaction rates and $K_{S}$ values increase with the head group size of surfactants. It was also observed that the reaction rate increases with the surfactant concentration when the surfactant concentration is low and then decreases with further increase in the surfactant concentration. It seems that with increase in the surfactant concentration, different interactions are involved between substrate and surfactants 
<smiles></smiles>

FIgURE 5: Decarboxylation of substrates 6-NBIC and 6-NBIC-5-Me [41].

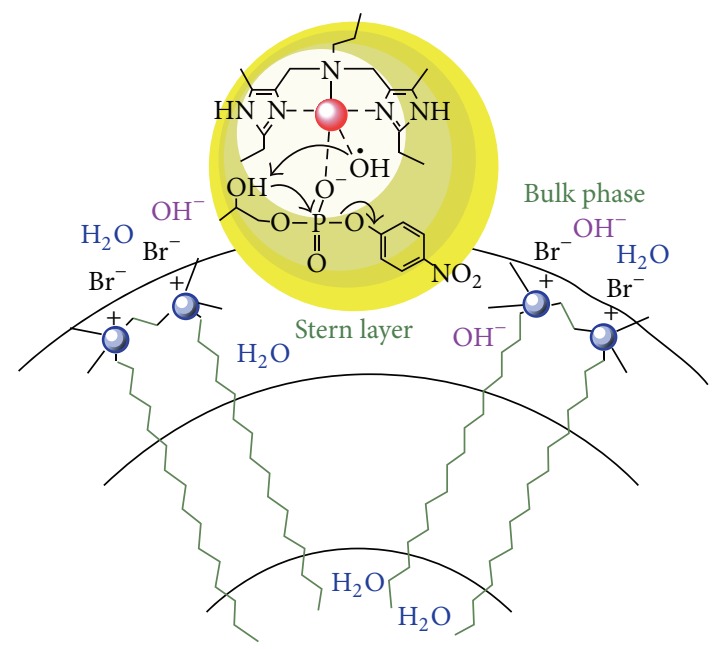

FIGURE 6: Catalytic cleavage of 2-hydroxypropyl p-nitrophenyl phosphate by $\mathrm{Zn}$ (II) complex in the Stern layer of gemini 16-2-16 micelles [45].

molecules in these two cases. But, using the pseudophase model, only one $k_{m}$ and $K_{S}$ value are calculated for the interaction of substrate with each of these surfactants in the whole range of surfactant concentration.

On the other hand, surfactant chain length can affect its interaction with substrates $[42,43]$. The kinetics study of the acid hydrolysis of anionic $N$-methyl- $N$-nitroso- $p$ toluenesulfonamide (MNTS) in media containing different cationic micellar aggregates LTAB, TTAB, CTAB, and $\beta$ cyclodextrin ( $\beta$-CD) [42] shows that the $K_{S}$ values of interaction between MNTS and surfactants increase with the chain length of surfactants. As reported [44], using cationic gemini surfactants with longer chain length increases the cleavage of carboxylate ester.

Jiang et al. [45] studied effects of increasing in both charge and chain length of surfactant. They investigated the cleavage of phosphate diesters mediated by Zn(II) complex in micellar solutions of cationic gemini 16-2-16 and CTAB, Figure 6. They observed that the cleavage rate of diester using CTAB is only about $40 \%$ of that using gemini 16-2-16 micelles under comparable conditions. This is due to the doubling of chain length and charge of gemini 16-2-16 compared to CTAB.

3.5. Enzymatic Reactions. Polyphenol oxidase (PPO) extracted from table beet leaves [46], potato leaf [47], persimmon fruit [48], and $\alpha$-chymotrypsin [49] was activated in the presence of SDS, SDS/DS mixed micelles, SDS, and DTAB, respectively, and their activities, due to denaturation, are decreased at higher surfactant concentrations. The kinetic parameters of interaction of two samples of PPO with surfactants $[46,47]$ were calculated by the stoichiometric model [6]. Results show that the positive cooperativity is observed during these interactions. But, activity of PPO extracted from beet root [50] is increased in the applied SDS concentration range and its kinetic parameters were calculated using the Hill equation that is similar to (6) used in the cooperativity model. For soluble PPO, the values of Hill coefficient $\left(n_{H}\right)$ of tyramine, dopamine, L-tyrosine, and L-DOPA substrates were $2.2,2.7,3.9$, and 4.2 , indicating that the number of SDS molecules needed for activation is higher for more hydrophilic substrates. These results corroborate that the ability of SDS to activate the enzyme involves a limited conformational change due to the binding of small amounts of SDS [51]. The access of hydrophobic substrates to the active site is favored since the first molecules of SDS are bound to the enzyme, while hydrophilic substrates require a deeper change for full access (activity).

Enzymatic synthesis using lipase in organic solvents has several advantages $[52,53]$. The solubility of nonpolar substrates is increased in organic solvents, and the reaction direction can be shifted to favor synthesis over hydrolysis. However, like all other natural enzymes, organic solvents easily denature lipase. To avoid the deactivation of enzyme in organic media, modification of enzyme surface by coating it with surfactants has been studied [52]. For example, it was observed that whereas the unmodified lipase from $B$. cepacia was insoluble in tert-butyl alcohol, the propylene glycol monostearate-coated lipase exhibited an enhanced solubility in tert-butyl alcohol at the reaction temperature [52]. The formation of reverse micelles stabilized the enzyme in the organic solvent; otherwise, the enzyme would have been denatured by removing the surrounding microaqueous layer, Figure 7.

3.6. Isomerization, Ligand Exchange, and Radical Reactions. Gille et al. [54] studied the thermal cis-trans-isomerization of $4,4^{\prime}$-nitroanilinoazobenzene dye in the presence SDS, TX-100, and Igepal CA-520. In microheterogeneous water/surfactant solutions isomerization rate constant values of selected azo dyes were strongly dependent on the concentrations of SDS and TX-100 in water and varied with the composition of bicontinuous microemulsions of Igepal 


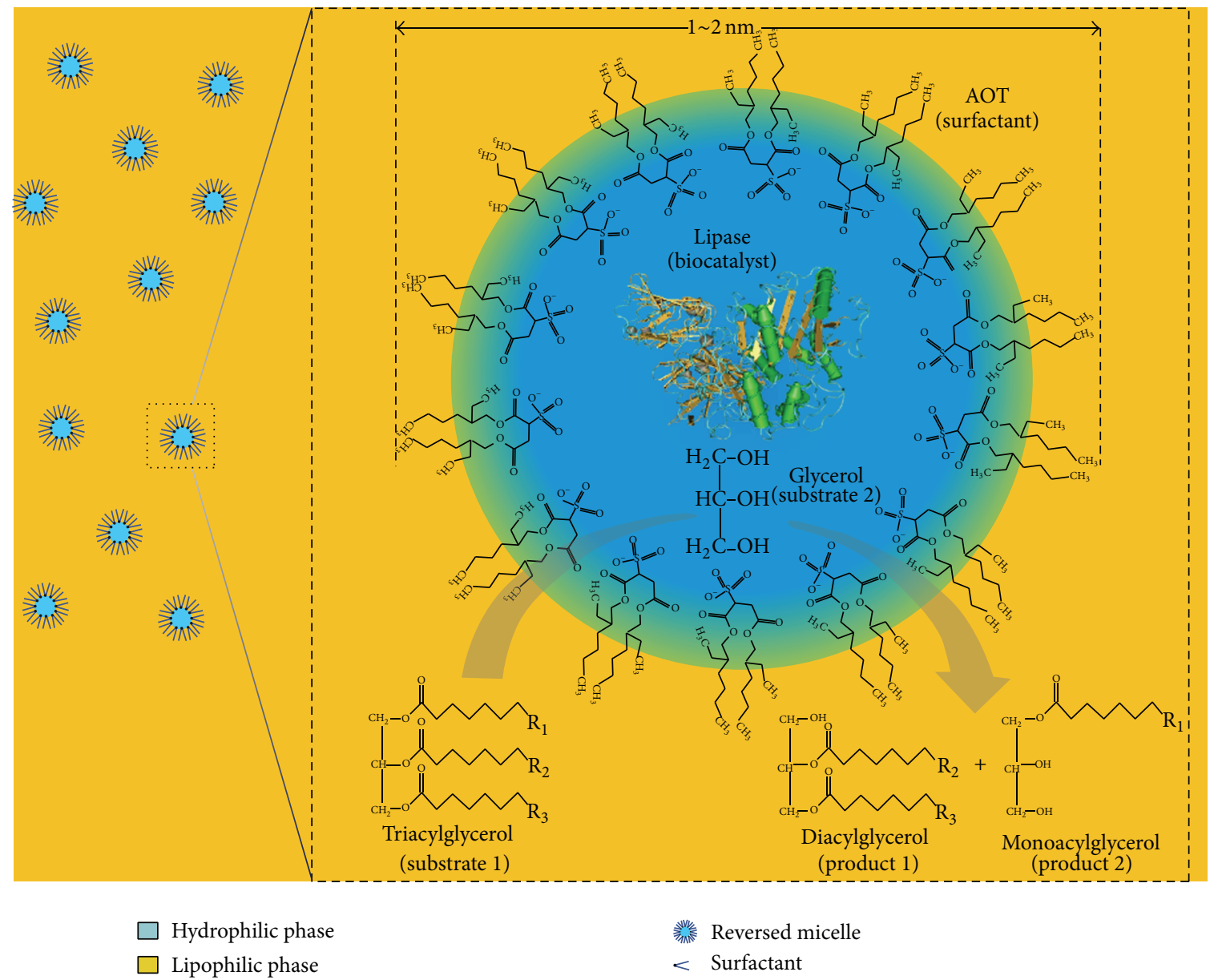

FIGURE 7: Schematic representation of AOT/isooctane reversed micellar system [53].

CA-520/heptane/water. The large spread of isomerization rate constants is in part due to varying microviscosity.

They showed that the trans-azo dyes have a constant balancing average microenvironment in the water/surfactant interface layer in a wide range of micelle concentrations. The isomerization rates of cis-isomer decrease by an order of magnitude with increasing the surfactant concentration, in part due to increasing microviscosity.

The rate of ligand substitution reaction between $\mathrm{Fe}(\mathrm{CN})_{5} \mathrm{H}_{2} \mathrm{O}^{3-}$ and pyrazine is decreased in the presence of CTAB [55]. The kinetic data showed that both nonmicellized and micellized CTAB are operative kinetically and interact with $\mathrm{Fe}(\mathrm{CN})_{5} \mathrm{H}_{2} \mathrm{O}^{3-}$. The pseudophase model can be used to study this interaction only for CTAB concentrations above its CMC and the calculated $K_{S}$ and $k_{m}$ were $260 \mathrm{M}^{-1}$ and $12.7 \mathrm{~s}^{-1}$, respectively. This strong interaction competes with the ligand substitution reaction. Similarly, the study of substitution rate of 4-cyanopyridine (4-CNpy) in $\mathrm{Fe}(\mathrm{CN})(4-\mathrm{CNpy})^{3-}$ by $\mathrm{S}_{2} \mathrm{O}_{8}{ }^{2-}$ in the presence of CTAB and TTAB shows that the longer the chain length of surfactant is, the more the reaction rates decreased [56]. On the other hand, it was observed that the reaction rate is not influenced by changes in the concentration of TX-100 and SDS. This observation shows the importance of preliminary electrostatic and then hydrophobic interactions of surfactants and substrates on the ligand substitution reaction rate.

Graciani et al. [57] showed that the rate of substitution of bipyridine (bpy) in $\mathrm{Fe}(\mathrm{CN})_{4}(\mathrm{bpy})^{2-}$ by $\mathrm{S}_{2} \mathrm{O}_{8}{ }^{2-}$ increases in the presence of zwitterionic surfactant SB3-14. The moderate interaction of positive headgroup of SB3-14 with substrates increases their concentrations on the surface of SB3-14 micelles and increases the reaction rate. Here, the authors calculated binding constants of SB3-14 to $\mathrm{Fe}(\mathrm{CN})_{4}(\mathrm{bpy})^{2-}$ and $\mathrm{S}_{2} \mathrm{O}_{8}{ }^{2-}$ separately using kinetic data in the pseudophase model and using conductometry data, respectively.

Emulsion polymerization is an example for radical reactions in the presence of surfactants [58-60]. Tang et al. [60] studied copolymerization of methyl methacrylate, butyl acrylate, and styrene in combination with a water-soluble anionic monomer (methacrylic acid or acrylic acid) and a nonionic monomer ( $N$-methylol acrylamide). The emulsifier surfactant, DSB, at a level greater than its CMC generated particle nuclei by micelle nucleation and controlled the particle size, particle size distribution, and the rate of polymerization.

3.7. Nucleophilic Reactions. Studies show that the reaction rates of a number of nucleophilic reactions of hydroxide ion with neutral compounds in the presence of cationic 
TABLE 1: Parameters obtained from stoichiometric model for interaction of $\mathrm{ME}^{2+}$ with SDS at 283-303 K [83].

\begin{tabular}{|c|c|c|c|c|c|c|c|c|}
\hline$T(\mathrm{~K})$ & Region & $\begin{array}{c}\mathrm{sc} \\
(\mathrm{mM})\end{array}$ & $\begin{array}{c}\begin{array}{c}k_{\mathrm{sc}} \\
\left(\mathrm{M}^{-1} \min ^{-1}\right)\end{array} \\
\end{array}$ & Samiey equation & $E_{S}$ & $\log K$ & $n$ & Cooperativity \\
\hline \multirow{3}{*}{283} & 1 st & 0.0 & 110.75 & $\ln k^{\prime}=-1084.72[\mathrm{SDS}]_{t}+4.70$ & 2552.2 & 4.28 & 1.33 & \multirow{3}{*}{$\downarrow-$} \\
\hline & 2nd & 0.97 & 39.00 & $\ln k^{\prime}=-438.05[\mathrm{SDS}]_{t}+4.06$ & 1030.7 & 4.22 & 1.49 & \\
\hline & $3 \mathrm{rd}$ & 4.80 & 7.51 & $\ln k^{\prime}=-87.73[\mathrm{SDS}]_{t}+2.41$ & 206.4 & 2.38 & 1.11 & \\
\hline \multirow{3}{*}{293} & 1 st & 0.0 & 246.00 & $\ln k^{\prime}=-981.53[\mathrm{SDS}]_{t}+5.50$ & 2391.0 & 4.07 & 1.29 & \\
\hline & 2nd & 0.97 & 95.29 & $\ln k^{\prime}=-379.99[\mathrm{SDS}]_{t}+4.92$ & 925.7 & 3.88 & 1.41 & \\
\hline & $3 \mathrm{rd}$ & 4.80 & 21.63 & $\ln k^{\prime}=-68.87[\mathrm{SDS}]_{t}+3.41$ & 167.8 & 2.46 & 1.24 & \\
\hline \multirow{3}{*}{303} & 1 st & 0.0 & 516.88 & $\ln k^{\prime}=-739.72[\mathrm{SDS}]_{t}+6.25$ & 1863.5 & 3.75 & 1.24 & \multirow{3}{*}{$\downarrow-$} \\
\hline & 2nd & 0.97 & 253.66 & $\ln k^{\prime}=-350.77[\mathrm{SDS}]_{t}+5.87$ & 883.6 & 3.75 & 1.38 & \\
\hline & $3 \mathrm{rd}$ & 4.80 & 65.05 & $\ln k^{\prime}=-70.46[\mathrm{SDS}]_{t}+4.52$ & 177.5 & 2.54 & 1.28 & \\
\hline
\end{tabular}

Dimension of $E_{S}$ is in $\mathrm{kJ}(\mathrm{mol} \text { molar(surfactant) })^{-1}$. Dimension of SDS concentration in the Samiey equation is in M. Dimension of $K$ is in $\mathrm{M}^{-n}$.

surfactants first increase and then decrease with increase in surfactant concentration [61-68] and the catalytic effect of cationic surfactants increases with the increase of their chain length $[61,66,68]$. Also, the reaction rate decreases in the presence of anionic surfactants $[63,65,67,69]$ and decreases with increase in the surfactant chain length [70]. In the former case, the formation of positively charged cationic surfactant/substrate complex promotes the reaction rate and then the interaction of more cationic surfactant molecules (having hydrophobic chains) with substrate decreases its interaction with negatively charged hydroxide ions. But, in the pseudophase model only one kind of interaction is considered within the whole surfactant concentration range and only one binding constant is calculated. In the latter case, the interaction of anionic surfactants with neutral substrates increases the electronic repulsion between the resulted complex and hydroxide ions.

On the other hand, the reaction rates of a number of nucleophiles (other than hydroxide ion) with neutral [71-73] and anionic [74-79] substrates are increased in the presence of cationic surfactants. It was observed that the increase in the chain length of cationic surfactants [75] and adding TX-100 [79] to the reaction media decreases the reaction rate. Also, results show that adding organic cosolvents [76-78] to the surfactant-contained media further decreases the reaction rate compared to that in the presence of surfactant only. These observations are due to the added organic cosolvents increase the CMC of surfactants and the interaction of TX-100 with cationic surfactants (in their mixed micelles) competes for its interaction with substrate molecules.

In addition to interaction with substrate molecules, surfactants sometimes can form ion pairs with them. As an example, it has been reported that SDS attacks cationic crystal violet dye and causes the formation of dye-surfactant ion pair [80].

As reported, reactions of some triphenylmethane dyes with hydroxide ion (fading) in the presence of surfactants have been studied by cooperativity, pseudophase, and stoichiometric models [81-84]. For comparing the results obtained from these models, the fading rate of cationic methyl green $\left(\mathrm{ME}^{2+}\right)$ dye in the presence of SDS [83] is studied. According to the stoichiometric model, in the used concentration range of SDS, there are three regions (or three kinds of interactions) at each temperature and the data of collected below the CMC are used in the calculations, Table 1.

Preliminary electrostatic and then hydrophobic interactions of SDS with $\mathrm{ME}^{2+}$ decrease the positive charge of $\mathrm{ME}^{2+}$ and decrease the reaction rate of $\mathrm{ME}^{2+}$ with hydroxide ion. With the increase of SDS concentration, the reaction rate decreases and thus $k_{S}=0$ in each region. Also, from the first to the third region, the impact of SDS on the reaction rate decreases and thus $E_{S}$ values decrease. At each temperature, from the first to the third region, the $(K)^{1 / n}$ values in each region decrease and thus the cooperativity of reaction is negative. Reactions in the first and second regions are exothermic and those in the third region are endothermic, resulting in a negative value of $\Delta H_{\text {tot }}$. Using the data of different regions of SDS and TX-100, the data of fading reaction of $\mathrm{ME}^{2+}$ in their mixtures was analyzed and stoichiometric ratios and binding constants of them with $\mathrm{ME}^{2+}$ were calculated.

According to the cooperativity model, the interaction of SDS with $\mathrm{ME}^{2+}$ is endothermic and $k_{S}=0$ and, at all temperatures, the cooperativity of process is positive. The data of fading reaction in the presence of SDS did not fit to the pseudophase model. This example shows that the obtained results are not similar to each other due to the different presumptions used in pseudophase, cooperativity, and stoichiometric models.

\section{Conclusions}

This review discusses effects of different kinds of surfactants in a series of chemical reactions including Diels-Alder, redox, photochemical, decomposition, enzymatic, isomerization, ligand exchange, radical, and nucleophilic reactions. These interactions were catalyzed or inhibited via the change in the dielectric constant of microenvironment or/and the charge of substrate molecules. As observed in all discussed examples, preliminary electrostatic and then hydrophobic interactions occur between surfactants and substrate molecules. Substrate/surfactant interactions are studied using pseudophase, cooperativity, and stoichiometric models. Due to different 
assumptions made in these models, results obtained from them may be different from each other.

\section{Acronyms and Proprietary Names for Some Surfactants}

\begin{tabular}{|c|c|}
\hline Brij 35: & Dodecyltricosaethylene glycol ether \\
\hline Brij 97: & Polyoxyethylene-10-oleyl ether \\
\hline CPC: & $\mathrm{N}$-Cetylpyridinium chloride \\
\hline CTAB: & Cetyltrimethylammonium bromide \\
\hline C12E6: & $\begin{array}{l}\text { Hexakis(ethylene glycol)monododecyl } \\
\text { ether }\end{array}$ \\
\hline CTEAB: & Cetyltriethylammonium bromide \\
\hline CTPAB: & Cetyltrin-propylammonium bromide \\
\hline CTBAB: & Cetyltrin-butylammonium bromide \\
\hline DS: & Dodecanesulfonic acid \\
\hline DSB: & $\begin{array}{l}\text { Sodium alkylated diphenyl ether } \\
\text { disulfonate }\end{array}$ \\
\hline DTAC: & Dodecyltrimethylammonium chloride \\
\hline Gemini 16-2-16: & $\begin{array}{l}\text { Bis(hexadecyl dimethyl ammonium) } \\
\text { ethane bromide }\end{array}$ \\
\hline Igepal CA-520: & p-Isooctylphenyl-pentaethylenglycolether \\
\hline LTAB: & Lauryltrimethylammonium bromide \\
\hline NaBDS: & $\begin{array}{l}\text { Sodium salt of bis(1-dodecenylsuccinamic } \\
\text { acid) }\end{array}$ \\
\hline SB3-14: & $\begin{array}{l}N \text {-Tetradecyl- } N, N \text {-dimethyl-3-ammonio- } \\
\text { 1-propanesulfonate }\end{array}$ \\
\hline SB3-16: & $\begin{array}{l}N \text {-Hexadecyl- } N, N \text {-dimethyl-3-ammonio- } \\
\text { 1-propanesulfonate }\end{array}$ \\
\hline SDS: & Sodium dodecyl sulfate \\
\hline Septonex: & Carbethopendecinium bromide \\
\hline TMN-10: & $\begin{array}{l}\text { 2,6,8-Trimethyl-4- } \\
\text { nonyloxypolyethyleneoxyethanol }\end{array}$ \\
\hline TMN-6: & 2-(2,6,8-Trimethyl-4-nonyloxy)ethanol \\
\hline Triton X-100: & $\begin{array}{l}\text { Polyethylene glycol [4-(1,1,3,3-tetramethyl } \\
\text { butyl)phenyl] ether }\end{array}$ \\
\hline & Tetradecyltrimethylammonium bromide \\
\hline & Polyethylene oxide sorbitan monooleate. \\
\hline
\end{tabular}

\section{Conflict of Interests}

The authors declare that there is no conflict of interests regarding the publication of this paper.

\section{References}

[1] D. Myers, Surfactant Science and Technology, John Wiley and Sons, Hoboken, NJ, USA, 2006.

[2] F. M. Menger and C. A. Littau, "Gemini surfactants: synthesis and properties," Journal of the American Chemical Society, vol. 113, no. 4, pp. 1451-1452, 1991.

[3] http://en.wikipedia.org/wiki/Micelle.

[4] F. M. Menger and C. E. Portnoy, "On the chemistry of reactions proceeding inside molecular aggregates," Journal of the American Chemical Society, vol. 89, no. 18, pp. 4698-4703, 1967.

[5] D. Piszkiewicz, "Micelle catalyzed reactions are models of enzyme catalyzed reactions which show positive homotropic interactions," Journal of the American Chemical Society, vol. 98, no. 10, pp. 3053-3055, 1976.
[6] B. Samiey, K. Alizadeh, M. A. Moghaddasi, M. F. Mousavi, and N. Alizadeh, "Study of kinetics of bromophenol blue fading in the presence of SDS, DTAB and Triton X-100 by classical model," Bulletin of the Korean Chemical Society, vol. 25, no. 5, pp. 726-736, 2004.

[7] S. Otto and J. B. F. N. Engberts, "Diels-Alder reactions in micellar media," in Reactions and Synthesis in Surfactant Systems, J. Texter, Ed., chapter 9, pp. 247-263, Marcel Dekker, New York, NY, USA, 2011.

[8] G. K. Van Wel, J. W. Wijnen, and J. B. F. N. Erigberts, "Solvent effects on a diels-alder reaction involving a cationic diene: consequences of the absence of hydrogen-bond interactions for accelerations in aqueous media," Journal of Organic Chemistry, vol. 61, no. 25, pp. 9001-9005, 1996.

[9] E. B. Mubofu and J. B. F. N. Engberts, "Surfactant-assisted specific-acid catalysis of Diels-Alder reactions in aqueous media," Journal of Physical Organic Chemistry, vol. 20, no. 10, pp. 764-770, 2007.

[10] I. Hunt and C. D. Johnson, "Dials-Alder reaction of fumaronitrile and cyclopentadiene in water: the influence of cosolutes," Journal of the Chemical Society, Perkin Transactions 2, no. 7, pp. 1051-1056, 1991.

[11] T. Rispens and J. B. Engberts, "Micellar catalysis of Diels-Alder reactions: substrate positioning in the micelle," The Journal of Organic Chemistry, vol. 67, no. 21, pp. 7369-7377, 2002.

[12] A. Simonyan and I. Gitsov, "Linear-dendritic supramolecular complexes as nanoscale reaction vessels for "green" chemistry. Diels-Alder reactions between fullerene $\mathrm{C}_{60}$ and polycyclic aromatic hydrocarbons in aqueous," Langmuir, vol. 24, no. 20, pp. 11431-11441, 2008.

[13] R. Braun, F. Schuster, and J. Sauer, "(4+2)-cycloadditionen in Micellen: ein vergleich des produktspektrums und der reaktionsgeschwindigkeit mit reaktionen in Lösung," Tetrahedron Letters, vol. 27, no. 11, pp. 1285-1288, 1986.

[14] G. B. van de Langkruis and J. B. F. N. Engberts, "Micellar effects on the reaction of (arylsulfonyl)alkyl arenesulfonates with hydroxide ion. 1. Microenvironmental and substituent effects in the stern layer of cationic micelles," Journal of Organic Chemistry, vol. 49, no. 22, pp. 4152-4157, 1984.

[15] S. Otto, F. Boccalatti, and J. B. F. N. Engberts, "A chiral Lewisacid-catalyzed Diels-Alder reaction. Water-enhanced enantioselectivity," Journal of the American Chemical Society, vol. 120, no. 17, pp. 4238-4239, 1998.

[16] N. Kambo and S. K. Upadhyay, "Antagonism in (conventional anionic-gemini anionic) mixed micelle catalyzed oxidation of D-fructose by alkaline chloramine-T,' International Journal of Chemical Kinetics, vol. 41, no. 2, pp. 123-132, 2009.

[17] A. Rodríguez, M. del Mar Graciani, M. Muñoz, and M. L. Moyá, "Study of the bromide oxidation by bromate in zwitterionic micellar solutions," International Journal of Chemical Kinetics, vol. 32, no. 6, pp. 388-394, 2000.

[18] B. Saha, S. Sarkar, and K. M. Chowdhury, "Micellar effect on quinquivalent vanadium ion oxidation of $\mathrm{D}$-glucose in aqueous acid media: a kinetic study," International Journal of Chemical Kinetics, vol. 40, no. 5, pp. 282-286, 2008.

[19] A. K. Das, M. Islam, and R. Bayen, "Studies on kinetics and mechanism of oxidation of D-sorbitol and D-mannitol by cerium (IV) in aqueous micellar sulfuric acid media," International Journal of Chemical Kinetics, vol. 40, no. 8, pp. 445-453, 2008. 
[20] A. M. A. Morshed and Z. Khan, "Role of manganese(II), micelles, and inorganic salts on the kinetics of the redox reaction of L- sorbose and chromium(VI)," International Journal of Chemical Kinetics, vol. 35, no. 11, pp. 543-554, 2003.

[21] K. Hartani and Z. Khan, "Micellar catalysis on the redox reaction of glycolic acid with chromium(VI)," International Journal of Chemical Kinetics, vol. 33, no. 6, pp. 377-386, 2001.

[22] M. A. Malik, F. M. Al-Nowaiser, N. Ahmad, and Z. Khan, "Kinetics of $\mathrm{MnO}_{4}^{-}$oxidation of succinic acid in aqueous solution of cetyltrimethylammonium bromide," International Journal of Chemical Kinetics, vol. 42, no. 12, pp. 704-712, 2010.

[23] Z. Zaheer and Rafiuddin, "Nucleation and growth kinetics of silver nanoparticles prepared by glutamic acid in micellar media," International Journal of Chemical Kinetics, vol. 44, no. 10, pp. 680-691, 2012.

[24] R. G. Chaudhuri and S. Paria, "Growth kinetics of sulfur nanoparticles in aqueous surfactant solutions," Journal of Colloid and Interface Science, vol. 354, no. 2, pp. 563-569, 2011.

[25] L. M. Liz-Marzán and I. Lado-Touriño, "Reduction and stabilization of silver nanoparticles in ethanol by nonionic surfactants," Langmuir, vol. 12, no. 15, pp. 3585-3589, 1996.

[26] P. V. Subba Rao, G. Krishna Rao, K. Ramakrishna, G. Rambabu, and A. Satyanarayana, "Kinetics of some electron-transfer reactions of iron(III)-2,2' -bipyridyl complex. Micellar effect of sodium dodecyl sulphate," International Journal of Chemical Kinetics, vol. 29, no. 3, pp. 171-179, 1997.

[27] K. C. Rajanna, K. N. Reddy, U. U. Kumar, and P. K. Sai Prakash, "A kinetic study of electron transfer from l-ascorbic acid to sodium perborate and potassium peroxy disulphate in aqueous acid and micellar media," International Journal of Chemical Kinetics, vol. 28, no. 3, pp. 153-164, 1996.

[28] T. Majumdar, H. K. Mandal, P. Kamila, and A. Mahapatra, "Influence of polymer-surfactant interactions on the reactivity of the $\mathrm{Co}^{I I}-\mathrm{Fe}^{I I}$ redox couple," Journal of Colloid and Interface Science, vol. 350, no. 1, pp. 212-219, 2010.

[29] A. Rodríguez, M. Del Mar Graciani, R. Balahura, and M. L. Moyá, "Micellar effects on the electron transfer reaction within the ion pair $\left[\left(\mathrm{NH}_{3}\right)_{5} \mathrm{Co}(\mathrm{N} \text {-cyanopiperidine })\right]^{3+} /\left[\mathrm{Fe}(\mathrm{CN})_{6}\right]^{4-}$," The Journal of Physical Chemistry, vol. 100, no. 42, pp. 16978$16983,1996$.

[30] I. Nêmcová and I. Jelínek, "The influence of some surfactants and inorganic salts on the stability of diethazine cation radical," Chemical Papers, vol. 47, no. 3, pp. 149-152, 1993.

[31] V. B. Gawandi, S. N. Guha, H. Mohan, and J. P. Mittal, "Kinetic and redox characteristics of semireduced species derived from phenosafranine in homogeneous aqueous and sodium dodecyl sulfate micellar media," International Journal of Chemical Kinetics, vol. 34, no. 1, pp. 56-66, 2002.

[32] F. S. Tanaka, R. G. Wien, and E. R. Mansager, "Effect of nonionic surfactants on the photochemistry of 3-(4-chlorophenyl)-1,1dimethylurea in aqueous solution," Journal of Agricultural and Food Chemistry, vol. 27, no. 4, pp. 774-779, 1979.

[33] R. A. Larson, C. T. Jafvert, F. Boscá, K. A. Marley, and P. L. Miller, "Effects of surfactans on reduction and photolysis (>290 $\mathrm{nm}$ ) of nitroaromatic compounds," Environmental Science and Technology, vol. 34, no. 3, pp. 505-508, 2000.

[34] Z. Shi, M. E. Sigman, M. M. Ghosh, and R. Dabestani, "Photolysis of 2-chlorophenol dissolved in surfactant solutions," Environmental Science and Technology, vol. 31, no. 12, pp. 35813587, 1997.

[35] C. Y. Kwan and W. Chu, "Reaction mechanism of photoreduction of 2,4-dichlorophenoxyacetic acid in surfactant micelles,"
Industrial and Engineering Chemistry Research, vol. 44, no. 6, pp. 1645-1651, 2005.

[36] W. K. Choy, W. Chu, and C. Y. Kwan, "Photochemical degradation of 2,4,6-trichlorophenol in the presence of a nonionic surfactant: $\mathrm{pH}$ control on reaction kinetics," Journal of Environmental Engineering, vol. 133, no. 6, pp. 641-645, 2007.

[37] M. Bettonia, L. Brinchib, T. Del Giaccob et al., "Surfactant effect on titanium dioxide photosensitized oxidation of 4dodecyloxybenzyl alcohol," Journal of Photochemistry and Photobiology A, vol. 229, no. 1, pp. 53-59, 2012.

[38] P. Baglioni, E. Rivara-Minten, C. Stenland, and L. Kevan, "Photoionization of $\mathrm{N}, \mathrm{N}, \mathrm{N}^{\prime}, \mathrm{N}^{\prime}$-tetramethylbenzidine in a mixed micelle of ionic and nonionic surfactants: electron spin-echo modulation and electron spin resonance studies," Journal of Physical Chemistry, vol. 95, no. 24, pp. 10169-10172, 1991.

[39] R. C. Meena, G. Singh, N. Tyagi, and M. Kumari, "Studies of surfactants in photogalvanic cells-NaLs-EDTA and azur-B system," Journal of Chemical Sciences, vol. 116, no. 3, pp. 179-184, 2004.

[40] C. Bravo-Diaz, M. J. Pastoriza-Gallego, S. Losada-Barreiro, V. Sanchez-Paz, and A. Fernandez-Alonso, "Dediazoniation of 1-naphthalenediazonium tetrafluoroborate in aqueous acid and in micellar solutions," International Journal of Chemical Kinetics, vol. 40, no. 6, pp. 301-309, 2008.

[41] L. Brinchi, R. Germani, L. Goracci, G. Savelli, N. Spreti, and P. di Profio, "Temperature effects upon aqueous micellar-assisted decarboxylation of 6-nitrobenzisoxazole-3-carboxylate and its 5-methyl derivative," Journal of Colloid and Interface Science, vol. 298, no. 1, pp. 426-431, 2006.

[42] I. Fernández, L. García-Río, P. Hervés, J. C. Mejuto, J. PérezJuste, and P. Rodríguez-Dafonte, " $\beta$-Cyclodextrin-micelle mixed systems as a reaction medium. Denitrosation of Nmethyl-N- nitroso -p-toluenesulfonamide," Journal of Physical Organic Chemistry, vol. 13, no. 10, pp. 664-669, 2000.

[43] L. Brinchi, R. Germani, E. Braccalenti, N. Spreti, M. Tiecco, and G. Savelli, "Accelerated decarboxylation of 6nitrobenzisoxazole-3-carboxylate in imidazolium-based ionic liquids and surfactant ionic liquids," Journal of Colloid and Interface Science, vol. 348, no. 1, pp. 137-145, 2010.

[44] B. Kumar, D. Tikariha, K. K. Ghosh, N. Barbero, and P. Quagliotto, "Kinetic study on effect of novel cationic dimeric surfactants for the cleavage of carboxylate ester," Journal of Physical Organic Chemistry, vol. 26, no. 8, pp. 626-631, 2013.

[45] W. Jiang, B. Xu, Q. Lin et al., "Cleavage of phosphate diesters mediated by $\mathrm{Zn}$ (II) complex in Gemini surfactant micelles," Journal of Colloid and Interface Science, vol. 311, no. 2, pp. 530536, 2007.

[46] J. Escribano, J. Cabanes, and F. García-Carmona, "Characterisation of latent polyphenol oxidase in table beet: effect of sodium dodecyl sulphate," Journal of the Science of Food and Agriculture, vol. 73, no. 1, pp. 34-38, 1997.

[47] A. Sánchez-Ferrer, F. Laveda, and F. García-Carmona, "Substrate-dependent activation of latent potato leaf polyphenol oxidase by anionic surfactants," Journal of Agricultural and Food Chemistry, vol. 41, no. 10, pp. 1583-1586, 1993.

[48] E. Núñez-Delicado, M. M. Sojo, F. García-Carmona, and A. Sánchez-Ferrer, "Partial purification of latent persimmon fruit polyphenol oxidase," Journal of Agricultural and Food Chemistry, vol. 51, no. 7, pp. 2058-2063, 2003.

[49] K. K. Ghosh and S. K. Verma, "Effects of head group of cationic surfactants on the hydrolysis of p-nitrophenyl acetate catalyzed 
by a-chymotrypsin," International Journal of Chemical Kinetics, vol. 41, no. 6, pp. 377-381, 2009.

[50] F. Gandía-Herrero, M. Jiménez-Atiénzar, J. Cabanes, F. GarcíaCarmona, and J. Escribano, "Differential activation of a latent polyphenol oxidase mediated by sodium dodecyl sulfate," Journal of Agricultural and Food Chemistry, vol. 53, no. 17, pp. 68256830, 2005.

[51] B. M. Moore and W. H. Flurkey, "Sodium dodecyl sulfate activation of a plant polyphenoloxidase. Effect of sodium dodecyl sulfate on enzymatic and physical characteristics of purified broad bean polyphenoloxidase," Journal of Biological Chemistry, vol. 265, no. 9, pp. 4982-4988, 1990.

[52] H.-J. Hsieh, G. R. Nair, and W.-T. Wu, "Production of ascorbyl palmitate by surfactant-coated lipase in organic media," Journal of Agricultural and Food Chemistry, vol. 54, no. 16, pp. 57775781, 2006.

[53] K. M. Park, C. W. Kwon, S. J. Choi et al., "Thermal deactivation kinetics of Pseudomonas fluorescens lipase entrapped in AOT/isooctane reverse micelles," Journal of Agricultural and Food Chemistry, vol. 61, no. 39, pp. 9421-9427, 2013.

[54] K. Gille, H. Knoll, and K. Quitzsch, "Rate constants of the thermal cis-trans isomerization of azobenzene dyes in solvents, acetone/water mixtures, and in microheterogeneous surfactant solutions," International Journal of Chemical Kinetics, vol. 31, no. 5, pp. 337-350, 1999.

[55] M. Del Mar Graciani, M. A. Rodríguez, and M. L. Moyá, "Study of the ligand substitution reaction $\mathrm{Fe}(\mathrm{CN})_{5} \mathrm{H}_{2} \mathrm{O}^{3-}+$ pyrazine in micellar solutions," International Journal of Chemical Kinetics, vol. 29, no. 5, pp. 377-384, 1997.

[56] G. Fernández, M. D. M. Graciani, A. Rodríguez, M. Múñoz, and M. L. Moyá, "Study of the reaction $\mathrm{Fe}(\mathrm{CN})_{5}(4-\mathrm{CNpy})^{3-}+\mathrm{S}_{2} \mathrm{O}_{8}^{2-}$ in aqueous salt and micellar solutions," International Journal of Chemical Kinetics, vol. 31, no. 2-3, pp. 229-235, 1999.

[57] M. D. M. Graciani, A. Rodríguez, M. Múñoz, and M. L. Moyá, "Study of the reaction $\mathrm{Fe}(\mathrm{CN})_{4}(\mathrm{bpy})^{2-}+\mathrm{S}_{2} \mathrm{O}_{8}^{2-}$ in sulfobetaine aqueous micellar solutions," International Journal of Chemical Kinetics, vol. 33, no. 4, pp. 225-231, 2001.

[58] C. S. Chern, "Emulsion polymerization mechanisms and kinetics," Progress in Polymer Science, vol. 31, no. 5, pp. 443-486, 2006.

[59] E. Özdeǧer, E. D. Sudol, M. S. El-Aasser, and A. Klein, "Role of the nonionic surfactant Triton X-405 in emulsion polymerization. III. Copolymerization of styrene and n-butyl acrylate," Journal of Polymer Science, Part A: Polymer Chemistry, vol. 35, no. 17, pp. 3837-3846, 1997.

[60] L. Tang, J. Yang, S. Zhang, and Y. Wu, "Emulsifier-minor emulsion copolymerization of BA-MMA-St-MAA (or AA)NMA," Journal of Applied Polymer Science, vol. 92, no. 5, pp. 2923-2929, 2004.

[61] B. Kumar, K. K. Ghosh, and P. R. Dafonte, "Comparative study of the cationic surfactants and their influence on the alkaline hydrolysis of acetylsalicylic acid," International Journal of Chemical Kinetics, vol. 43, no. 1, pp. 1-8, 2011.

[62] N. Singh, K. K. Ghosh, J. Marek, and K. Kuca, "Hydrolysis of carboxylate and phosphate esters using monopyridinium oximes in cationic micellar media," International Journal of Chemical Kinetics, vol. 43, no. 10, pp. 569-578, 2011.

[63] F. F. Al-Blewi, H. A. Al-Lohedan, M. Z. A. Rafiquee, and Z. A. Issa, "Kinetics of hydrolysis of procaine in aqueous and micellar media," International Journal of Chemical Kinetics, vol. 45, no. 1, pp. 1-9, 2013.
[64] S. K. Gangwar and M. Z. A. Rafiquee, "Kinetics of the alkaline hydrolysis of fenuron in aqueous and micellar media," International Journal of Chemical Kinetics, vol. 39, no. 11, pp. 638-644, 2007.

[65] S. K. Gangwar and M. Z. A. Rafiquee, "Kinetics of the alkaline hydrolysis of isoproturon in CTAB and NaLS micelles," International Journal of Chemical Kinetics, vol. 39, no. 1, pp. 39-45, 2007.

[66] A. Cuenca, "Surfactant effects on the reaction of 2-(4-cyanophenoxy)-quinoxaline with hydroxide ion," International Journal of Chemical Kinetics, vol. 38, no. 8, pp. 510-515, 2006.

[67] M. N. Al-Shamary, H. A. Al-Lohedan, M. Z. A. Rafiquee, and Z. A. Issa, "Micellar effects on aromatic nucleophilic substitution by the ANRORC mechanism. Hydrolysis of 2-chloro-3,5dinitropyridine," Journal of Physical Organic Chemistry, vol. 25, no. 8, pp. 713-719, 2012.

[68] A. S. Al-Ayed, M. S. Ali, H. A. Al-Lohedan, A. M. Al-Sulaim, and Z. A. Issa, "Effect of alkyl chain length, head group and nature of the surfactant on the hydrolysis of 1,3-benzoxazine2,4-dione and its derivatives," Journal of Colloid and Interface Science, vol. 361, no. 1, pp. 205-211, 2011.

[69] A. Malpica, M. Calzadilla, and H. Linares, "Micellar effect upon the reaction of hydroxide ion with coumarin," International Journal of Chemical Kinetics, vol. 30, no. 4, pp. 273-276, 1998.

[70] G. Astray, A. Cid, J. A. Manso, J. C. Mejuto, O. Moldes, and J. Morales, "Influence of anionic and nonionic micelles upon hydrolysis of 3-hydroxy-carbofuran," International Journal of Chemical Kinetics, vol. 43, no. 8, pp. 402-408, 2011.

[71] B. Kumar, M. L. Satnami, K. K. Ghosh, and K. Kuca, "Comparative studies on reaction of bis( $p$-nitrophenyl) phosphate and $\alpha$-nucleophiles in cationic micellar media," Journal of Physical Organic Chemistry, vol. 25, no. 10, pp. 864-871, 2012.

[72] K. K. Ghosh, J. Vaidya, and M. L. Satnami, "The $\alpha$-effect in micelles: nucleophilic substitution reaction of $p$-nitrophenyl acetate with $N$-phenylbenzohydroxamate ion," International Journal of Chemical Kinetics, vol. 38, no. 1, pp. 26-31, 2006.

[73] K. K. Ghosh, S. Bal, S. Kolay, and A. Shrivastava, "Comparative nucleophilic reactivities in carboxylate, phosphinate, and thiophosphate esters cleavage," Journal of Physical Organic Chemistry, vol. 21, no. 6, pp. 492-497, 2008.

[74] S. K. Sar, N. Rathod, and P. K. Pandey, "Nucleophilic debenzoylation of $p$-nitrophenyl benzoate in cationic micellar media," International Journal of Chemical Kinetics, vol. 42, no. 2, pp. 106112,2010 .

[75] M. M. Mohareb, K. K. Ghosh, and R. M. Palepu, "Kinetics of the reaction of methyl 4-nitrobenzenesulfonate $+\mathrm{Br}$ - in ethanol amine based surfactants," International Journal of Chemical Kinetics, vol. 38, no. 5, pp. 303-308, 2006.

[76] M. Muñoz, M. Del Mar Graciani, A. Rodríguez, and M. L. Moyá, "Effects of alcohols on micellization and on the reaction methyl 4-nitrobenzenesulfonate $+\mathrm{Br}^{-}$in cetyltrimethylammonium bromide aqueous micellar solutions," International Journal of Chemical Kinetics, vol. 36, no. 12, pp. 634-641, 2004.

[77] M. Del Mar Graciani, A. Rodríguez, G. Fernández, M. Muñoz, and M. L. Moyá, "Study of the reaction of methyl 4-nitrobenzenesulfonate and $\mathrm{Br}^{-}$in water-glycerol cationic micellar solutions," International Journal of Chemical Kinetics, vol. 40, no. 12, pp. 845-852, 2008.

[78] M. A. Rodríguez, M. Muñoz, M. del Mar Graciani, G. Fernández, and M. L. Moyá, "Effects of head group size on 
the reaction methyl 4-nitrobenzenesulfonate $+\mathrm{Br}^{-}$in waterethylene glycol cetyltrialkylammonium bromide micellar solutions," International Journal of Chemical Kinetics, vol. 39, no. 6, pp. 346-352, 2007.

[79] G. Fernández, A. Rodríguez, M. del Mar Graciani, M. Muñoz, and M. L. Moyá, "Study of the reaction methyl 4-nitrobenzene-sulfonate $+\mathrm{Cl}$ - in mixed hexadecyltrimethylammonium chloride-Triton X-100 micellar solutions," International Journal of Chemical Kinetics, vol. 35, no. 2, pp. 45-51, 2003.

[80] B. Samiey and F. Ashoori, "Kinetics of crystal violet fading in the presence of TX-100, DTAB and SDS," Acta Chimica Slovenica, vol. 58, no. 2, pp. 223-232, 2011.

[81] B. Samiey and A. R. Toosi, "Kinetics study of malachite green fading in the presence of TX-100, DTAB and SDS," Bulletin of the Korean Chemical Society, vol. 30, no. 9, pp. 2051-2056, 2009.

[82] B. Samiey and M. R. Dargahi, "Kinetics of brilliant green fading in the presence of TX-100, DTAB and SDS," Reaction Kinetics, Mechanisms and Catalysis, vol. 101, no. 1, pp. 25-39, 2010.

[83] B. Samiey and Z. Dalvand, "Kinetics of methyl green fading in the presence of TX-100, DTAB and SDS," Bulletin of the Korean Chemical Society, vol. 34, no. 4, pp. 1145-1152, 2013.

[84] B. Samiey and Z. Dalvand, "Study of fuchsin acid fading in micellar media," International Journal of Chemical Kinetics, vol. 46, no. 11, pp. 651-661, 2014. 

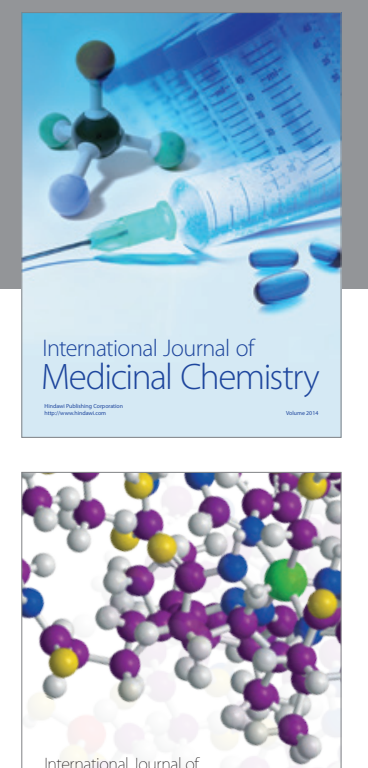

\section{Carbohydrate} Chemistry

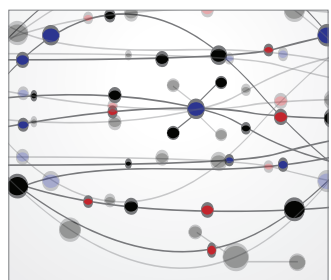

The Scientific World Journal
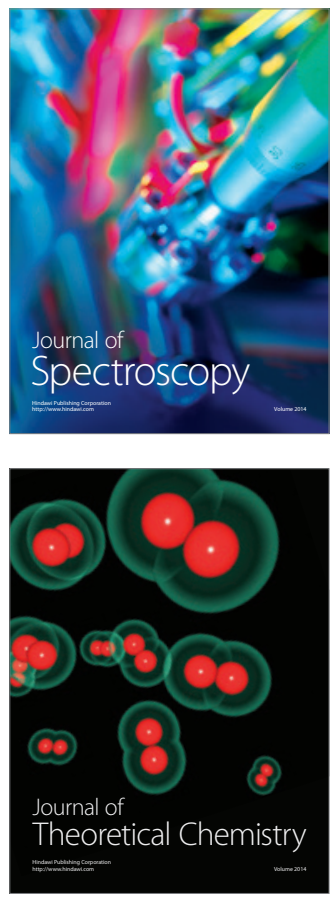
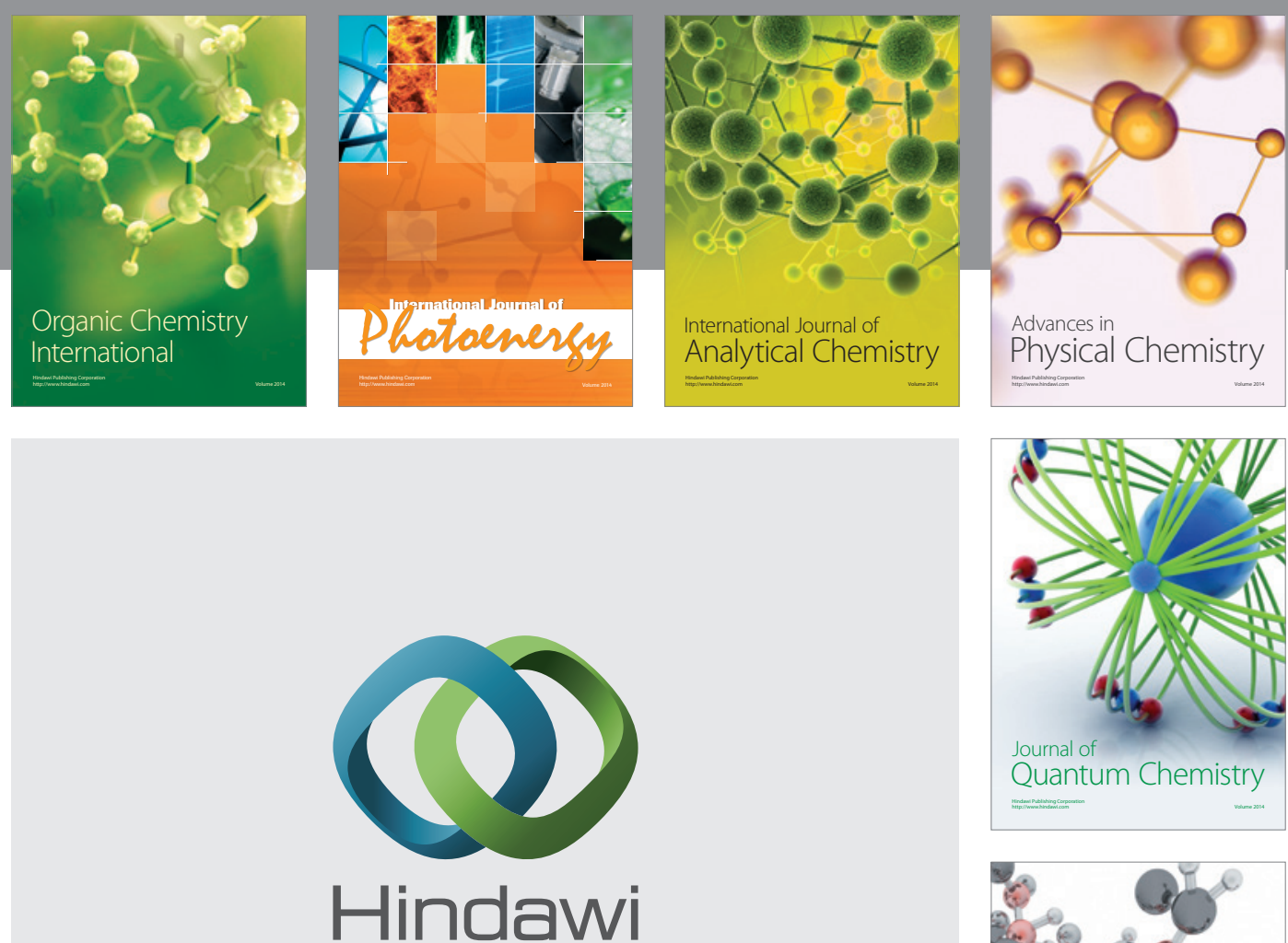

Submit your manuscripts at

http://www.hindawi.com

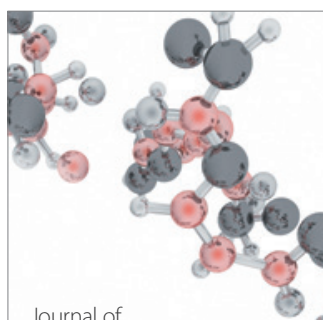

Analytical Methods

in Chemistry

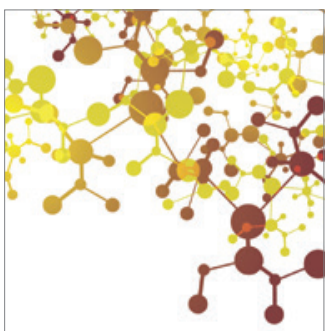

Journal of

Applied Chemistry

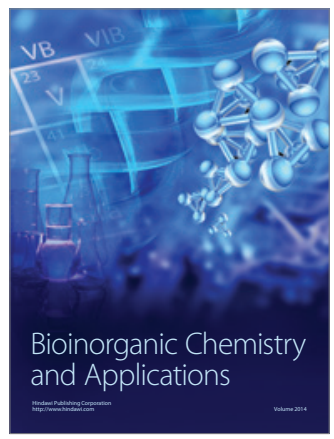

Inorganic Chemistry
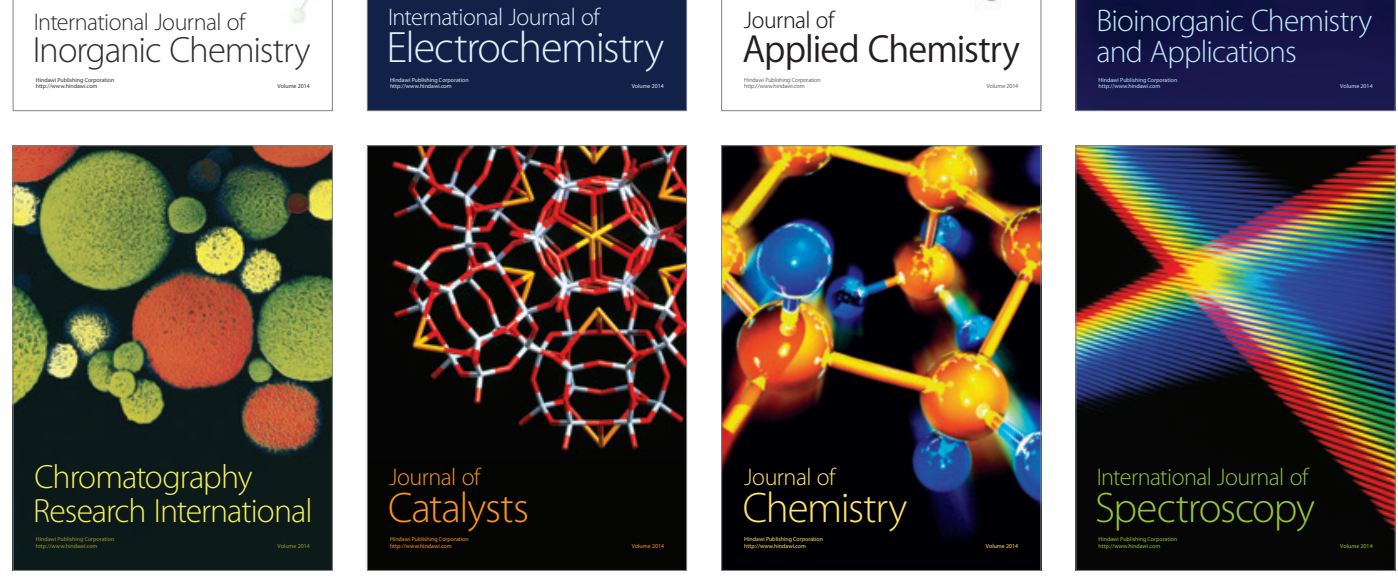